EESTI NSV TEADUSTE AKADEEMIA TOIMETISED. XVIII KÖIDE

KEEMIA * GEOLOOGIA. 1969, Nr. I

ИЗВЕСТИЯ АКАДЕМИИ НАУК ЭСТОНСКОИ ССР. ТОМ ХVII

Химия = ГЕОЛОГИя 1969. N 1

М. ГУБЕРГРНЦ, У. КИРСО

\title{
СТРУКТУРА, РЕАКЦИОННАЯ СПОСОБНОСТЬ И БИОЛОГИЧЕСКАЯ АКТИВНОСТЬ ФЕНОЛОВ
}

Биологическая активность органических соединений тесно связана с особенностями их электронной структуры. Так, подавляющая часть веществ, входящих в состав живых организмов и ответственных за жизнедеятельность, прннадлежит к системам, которым в силу их строения свойствен выраженный эффект сопряжения [ $\left.{ }^{1}\right]$. Выявление и количественное описание связей между структурой молекулы, ее реакционной способностью в процессах, протекающих in vitro (и потому более доступных для изучения), и бнологической активностью является одной из актуальных задач современной физической и биологической химин.

Настоящее сообщение посвящено попытке охарактеризовать гакие связи на основе анализа литературных и оригинальных материалов применительно к канцерогенной способности и токсичности фенолов.

\section{Канцерогенная активность органических соединений}

Попытки сопоставления сгруктуры и канщерогенных свойств некоторых органических веществ $\left[{ }^{2}\right]$ в связи с развитием квантовой биохимии вылились в относительно стройную теорию $\left[{ }^{1,3,4}\right]$. Авторы ее связывают канцерогенные свойства вещества с наличием в молекуле так называемых активных областей (вследствие специфичного распределения в ней электронной плотности), но отрицают однозначную связь их со способностью к замещению. Ряд экспериментальных работ, например $\left[{ }^{5-9}\right]$, противоречит некоторым положениям этой теории. В связи с этим выдзинута и обоснована гипотеза o перераспредєлении электронной плотности в молекуле канцерогена при взаимодействии в ткани, которое отвечает возбужденному ее состоянию $\left[{ }^{10}\right]$.

Наряду с «классическими» канцерогенами - конденсированными ароматическими уюлеводородами этим юидом биологической активности обладают и некоторые представители других классов органических соединений - фенолы, амины, азокрасители и др. ліри условии, что они способны участвовать в окислительно-восстановительных реакциях [11]. Что касается феколов, то некоторые исследователи склонны считать их не собственно канцерогенами, а лишь промоторами, по тем или иным причинам усиливающими активность других канцерогенных веществ [ $\left.{ }^{11-14}\right]$.

Другая концепция сводится к тому, что фенолы являются одновременно и канцерогенами, и промоторами. Она подкрепляется значительным экслериментальным материалом $\left[{ }^{15-20}\right]$. Так, наличие примесей в феноле существенно усиливает его канцерогенную активность: например, при воздействии на подопытных животных тщательно очищенного оксибензола опухоли возникают лишь в $37 \%$ случаев против $52 \%$ при использовании не очень чистого реагента $\left[{ }^{17}\right]$. Совместное же действие фенола и полициклического канцерогена оказывается более активным, чем каждого из компонентов такой смеси в отдельности (явление коканцерогенеза): под действием смеси оксибен- 
зола и 9,10-диметилбензантрацєна (ДМБА) на мышей число случаев возникновения опухолей возрастет до $40-75 \%$ против $5 \%$ при раздельном использовании каждого из реагентов в тождественных условиях [17].

По данным работ $\left[{ }^{17-19}\right]$, в ряду фенолов наиболее канцерогенными являются оксибензол и крезолы. Канщерогенная способность фенола сннжается при вводе в его молекулу длинных и особенно разветвленных алкильных групп. Аналогичным является действие таких заместителей, как карбоксильные, карбонильные и нитрогруппы $\left[{ }^{17},{ }^{20}\right]$. Тем не менее в цитированных работах отрицается наличне общей коррелятивной связи между реакщионной способностью фенола и его канцерогенностью.

Bсе описанные свойства фенолов и их проявление имеют сушественное практическое значение, в частности по двум соображениям. Первое из них заключается в том, что фенолы нередко встречаются в составе технических смесей, содержащих кклассическиеу канцерогены, например 3,4-бензпирен; к ним относятся и продукты термического разложения натуральных топлив $\left[{ }^{21-23}\right]$. Попытки же ослабить канцерогенные свойства таких смесей производились без прямого учета этого обстоятельства $\left[{ }^{22}\right]$. Второе соображение, более общего характера, заключается в том, что ряд соединений других классов в результате метаболизма в тканях превращается в оксисоединения (для примера укажем на характерное метаболическое гидроксилирование ароматических аминов в орто-положении) и может приобрести канцерогенные свойства ["1].

\section{Структура и канцерогенная активность фенолов}

Несмотря на сложность и запутанность вопроса, попытка установления закономерной связи между структурными особенностями и активностью фенолов в качестве промоторов или самостоятельных канцерогенов не представляется нам обреченной на полную неудачу. Чтобы доказать это, мы обработали экспериментальные данные из обстоятельной работы Боутвелла с сотрудниками $\left[{ }^{17}\right]$, в которой систематически изучена промоторная и канцерогенная активность различных представителей этого гомологического ряда. В этих опытах раствор фенола в ацетоне или бензоле, с добавкой $0,3 \%$ ДМБА или без нее, наносится на кожу белых мышей, причем величина дозы выбрана таким образом, чтобы исключить гибель животных вследствие отравления. Наблюдение за животными производилось в течение $12-20$ недель.

Всего в указанной работе поставлено тринадцать серий экспернментов с фенолами различного строения. Часть полученных данных, как показывает их достаточно строгий анализ, пригодна лишь для качественnого рассмотрения вопроса, ибо в ряде серий были использованы не эквимолярные количества фенолов различного строения, а равные весовые дозы. В случае значительных различий в величине молекулярного веса отдельных гомологов полученные данные нельзя считать сопоставимыми, особенно при количественной обработке.

Рассмотрение качественной картины приводит к заключению, что промоторной или канцерогенной способностью отличаются фенолы с такими заместителями, которые обладают положительным эффектом сопряжения $(+R)$, т. е. способствуют увеличению электронной плотности в бензольном ядре у реакционного центра (оксигруппы) и направляют электрофильные атаки в орто- или пара-положения. Напротив, наличи० в молекуле заместителей с отрицательным эффектом сопряжения $(-R)$ сводит на нет канцерогенные или промоторные свойства данного соединения. На биологическую активность молекулы в данном отношении в принципе не оказывает влияния знак индукционного эффекта заместителя: она присуща как алкилзамещенным фенолам с $+I$, так и хлор-, бром- или оксизамещенным с $-I$. 
Эти обобщения иллюстрируются рядом примеров, из которых наиболее показательны следующие. Промоторными или канцерогенными свойствами практически не обладает фенол с заместителями 2-CHО, $2-\mathrm{COOH}, 2-\mathrm{NO}_{2}, 4-\mathrm{NO}_{2}$, для которых характерен отрицательный эффект сопряжения (девятая серия). Напротив, эти свойства ярко выражены для $2,4,6$-трибромфенола $(+R,-I)$, резорцина $3-\mathrm{OH}(+R,-I)$ или орто-крезола $2-\mathrm{CH}_{3}(+R,+I)$. Биологическая активность хлорзамещенных фенолов $(+R,-I)$ убывает по мере увеличения их реакционной способности в электрофильных процессах: $2,4,6-\mathrm{Cl}_{3}<2,4 \mathrm{Cl}_{2}<$ $<2-\mathrm{Cl}<3-\mathrm{Cl}$ (шестая серия), причем свойства орто-замещенного гомолога не отклоняются от общей закономерности. При положительном же значении обоих эффектов - индукционного и сопряжения, например в двенадцатой серии для алкилфенолов, орто-замещенные отличаются пезакономерно повышенной биологической активностью.

Итак, классификация фенолов по структурным признакам и биологической активности приводит к заключению о наличии обратной зависимости между величиной электронной плотности у реакционного центра в ядре и канцерогенной или промоторной способностью. Сошлемся в подтверждение наших качественных выводов на работу $\left[{ }^{24}\right]$, согласно которой активные антиокислители не только не проявляют канцерогенных свойств, но даже оказывают противоположное действие на ткани и могут быть рекомендованы для использования в химиотерапии рака.

Для количественной хар актери стики описанных закономерностей по указанным ранее причинам удалось привлечь лишь сравнительно ограниченные данные из работы $\left[{ }^{17}\right]$. При их обработке мы сопоставили значения суммы полярных констант $\sigma$, характеризующие специфику строения молекулы данного фенола, с числом случаев $A$ появления опухолей у подопытных животных (выраженным в процентах от общего количества). Сопоставления были произведены для трех серий опытов, в которых число экспериментальных точек превышает четыре. Эти данные приведены в табл. 1.

Таблица I

Исходные данные для определения зависимости промоторной и канцерогенной активности фенолов $\left[{ }^{17}\right]$ от их строения

\begin{tabular}{|c|c|c|c|c|}
\hline & $\begin{array}{c}\text { Процент подопыт- } \\
\text { ных жквотных с } \\
\text { опухолями }\end{array}$ & & & 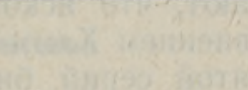 \\
\hline $\begin{array}{c}\text { в бензольном } \\
\text { ядре }\end{array}$ & $\begin{array}{l}\text { в том } \\
\text { чнсле } \\
\text { злока- } \\
\text { чествен- } \\
\text { ные } A^{\prime}\end{array}$ & $\begin{array}{l}\lg A^{A} \\
\left(\lg A^{1}\right)\end{array}$ & {$[25-27]$} & $\begin{array}{c}\text { Характернстика } \\
\text { реакционноћ̆ серии }\end{array}$ \\
\hline
\end{tabular}

\begin{tabular}{|c|c|c|c|c|c|}
\hline $\begin{array}{l}\stackrel{\mathrm{H}}{2}-\mathrm{CH}_{3} \\
3-\mathrm{CH}_{2} \\
3-\mathrm{CH}_{3} \\
-\mathrm{OH}\end{array}$ & $\begin{array}{l}64 \\
59 \\
50 \\
35 \\
17\end{array}$ & 0.0 & $\begin{array}{l}1,806 \\
1,771 \\
1,699 \\
1,544 \\
0.929\end{array}$ & $\begin{array}{l}0,0 \\
-0,19 \\
-0,07 \\
-0,15 \\
-0,40\end{array}$ & $\begin{array}{l}\text { С ер и я } 4: \\
0.3 \% \text { ДМБА в ацетоне + про- } \\
\text { мотор в бензоле; продолжи- } \\
\text { тельность } 12 \text { недель }\end{array}$ \\
\hline $\begin{array}{l}2,4-\left(\mathrm{CH}_{3}\right)_{2} \\
2,6-\left(\mathrm{CH}_{3}\right)_{2} \\
3,4-\left(\mathrm{CH}_{3}\right)_{2} \\
3,5-\left(\mathrm{CH}_{3}\right)_{2} \\
2-\mathrm{OH} \\
2.3-(\mathrm{OH})_{2}\end{array}$ & $\begin{array}{r}50 \\
30 \\
95 \\
40 \\
14 \\
4\end{array}$ & $\begin{array}{r}18 \\
11 \\
14 \\
5 \\
5 \\
0\end{array}$ & $\begin{array}{l}1.699 \\
1.480 \\
1.980 \\
1.600 \\
0,850 \\
0.130\end{array}$ & $\begin{array}{r}-0,34 \\
-0,38 \\
-0,22 \\
-0,14 \\
-0.43 \\
-0,83\end{array}$ & $\begin{array}{l}\text { С ер и я } 5: \\
0.3 \% \text { ДМБА в бензоле + про- } \\
\text { мотор в бензоле; продолжи- } \\
\text { тельность } 15 \text { недель }\end{array}$ \\
\hline $\begin{array}{l}\quad \mathrm{H} \\
2,4-\left(\mathrm{CH}_{3}\right)_{2} \\
2,5-\left(\mathrm{CH}_{3}\right)_{2} \\
2,6-\left(\mathrm{CH}_{3}\right)_{2} \\
3,4-\left(\mathrm{CH}_{3}\right)_{2} \\
3,5-\left(\mathrm{CH}_{3}\right)_{2}\end{array}$ & $\begin{array}{r}33 \\
31 \\
24 \\
8 \\
50 \\
55\end{array}$ & $\begin{array}{c}29 \\
12 \\
8 \\
(0) \\
14 \\
14\end{array}$ & $\begin{array}{l}1,52(1,46) \\
1,49(1,08) \\
1,38(0,90) \\
0.90(\ldots) \\
1,70(1,15) \\
1,74(1,15)\end{array}$ & $\begin{array}{l}0,0 \\
-0,34 \\
-0,26 \\
-0,38 \\
-0,22 \\
-0,14\end{array}$ & $\begin{array}{l}\text { Серия 10: } \\
\text { только промотор в } 6 \text { ензоле: про- } \\
\text { должительность } 20 \text { недель }\end{array}$ \\
\hline
\end{tabular}


Дальнейшая обработка произведена по принципу, заложенному в известном уравнении Хаммета-Тафта. Оно в обычном своем виде связывает реакционную способность и структурную характеристику данного класса соединений: $\lg k / k_{0}=\varrho \Sigma \sigma_{i}$, где $\quad \Sigma \sigma_{i}=\Sigma \sigma_{m}+\Sigma \sigma_{p}+$ $+\Sigma \sigma_{0}$. Произведенная нами модификация этого уравнения заключается в подстановке вместо величины $k$ значения $A$ из табл. 1 (см. в таблице данные для $\lg A): \lg A=\varrho \Sigma \sigma_{i}+\lg A_{0}$.

Корреляция данных произведена с помощью метода наименьших квадратов по методике, использованной нами ранее $\left[{ }^{28}\right]$. Для заместителей с отрицательным индукционным эффектом и положительным эффектом сопряжения наилучшие результаты дает использование $\sigma_{R}{ }^{0}$ шкалы $\left[{ }^{26}\right]$. Наличие нескольких оксигрупп в молекуле учитывается путем внесения поправки на статический фактор.

Таблица 2

Корреляционные уравнения для промоторно-канцерогенной активности фенолов

\begin{tabular}{|c|c|c|c|c|c|}
\hline Серия & $\begin{array}{c}\text { Число } \\
\text { экспери- } \\
\text { менталь- } \\
\text { ныХ точек }\end{array}$ & Уравненне & $r$ & $s$ & Прнмечання \\
\hline 3 & 5 & $\lg A=3,0434 \Sigma \sigma_{i}-2.5669$ & 0,9498 & 0,021 & $\begin{array}{l}\text { Отклоняется } \\
3.5-\left(\mathrm{CH}_{3}\right)_{2}\end{array}$ \\
\hline 4 & 4 & $\lg A=2,1012 \Sigma \sigma_{i}-1,8204$ & 0,9964 & 0,003 & $\begin{array}{l}\text { Отклоняется } \\
2-\mathrm{CH}_{3}\end{array}$ \\
\hline 10 & 5 & $\lg A=2,9389 \Sigma \sigma_{i}-2,2296$ & 0.8320 & 0,067 & $\begin{array}{l}\text { Отклоняется } \\
\text { оксибензол }\end{array}$ \\
\hline $10^{*}$ & 5 & $\lg A^{\prime}=1,5570 \Sigma \sigma_{i}-1,4469$ & 0,8320 & 0,100 & \\
\hline
\end{tabular}

* Примечание. Учнтывается чнсто канцерогенная активность фенолов (см табл, 1).

Результаты количественной обработки, приведенные в табл, 2, показывают, что искомая связь хорошо описывается модифицированным уравнением Хаммета--Тафта: коэффициент корреляции $r$ для четвертой и пятой серий биологических экспериментов составляет $0,95-0,99$, а стандартная ошибка $s-$ всего 0,002-0,040. Несколько хуже показатели при корреляции результатов десятой серии. Правда, в данном случае характеризуется не типичное для фенолов промоторное действие, а собственно канцерогенная их способность. Может быть, это обстоятельство в какой-то мере могло сказаться на величине погрешности и разбросе экспериментальных точек.

На рисунке в координатах $\lg A-\Sigma \sigma_{i}$ нанесены все обработанные экспериментальные точки и по ним проведена прямая 1 для некоторого «среднего» случая, с отклонением от него около 10\%. Она наглядно характеризует искомую нами функциональную связь между канцерогенно-промоторными свойствами и структурными особенностями фенолов. Зависимость же от строения фенолов их окисляемости и антиокислительной способности (т. е. способности участвовать в процессе окисления in vitro) количественно охарактеризована нами ранее $\left[{ }^{28}\right]$.

Итак, промоторно-канцерогенные свойства фенолов проявляются, повидимому, в нуклеофильной стадии, лимитирующей суммарную реакцию 
их в организме. Чувствительность ее в рассмотренных условнях колеблется в пределах $\underline{g}=2-3$ и составляет в среднем около 2,5 (см. рисунок). На этом основании представляется возможным априорное предсказание промоторно-канцерогенной активности фенола заданного строения до его биологического испытания.

Зависимость канцерогенной активности $A$ (прямая 1$)$ и токсичности $1 / C$ (прямая 2) фенолов от их структуры.

Обозначение точек по табл. 1: (1) - серия 4,

- серия 5, $\odot$ - серия 10: $О$ токсичность по данным $\left[{ }^{29}\right]$.

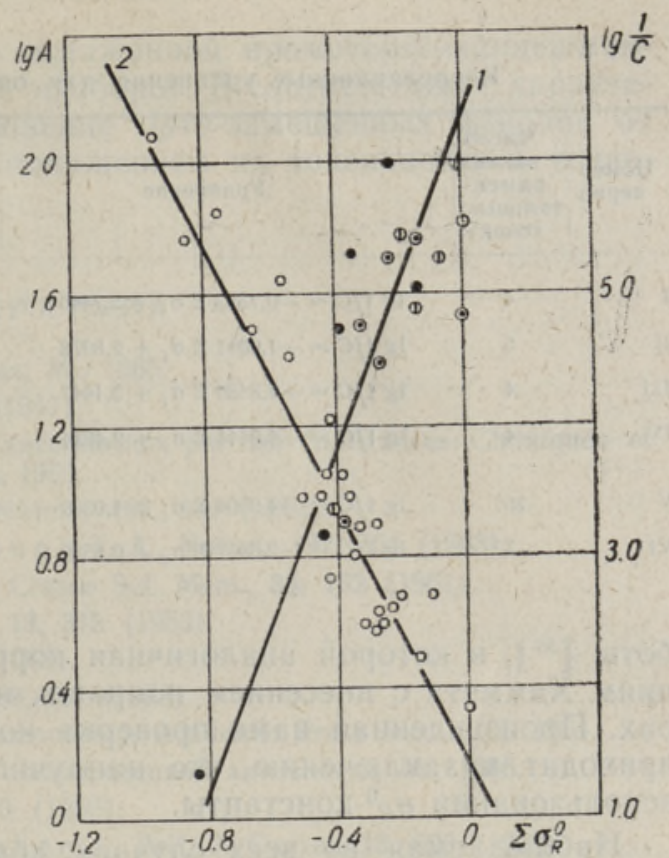

Наши выводы позволяют опровергнуть не только заключение авторов работ $\left[{ }^{17,20}\right]$ об отсутствии коррелятивной связи между структурой и канцерогенностью фенолов, но и одну из возможных гипотез о механизме их промоторного действия. Естественно было предположить, что при совместном вводе в живой организм молекул собственно канцерогена и фенола последний в силу своих антиокислительных свойств играет роль ингибитора окисления и предохраняет молекулу канцерогена от прежцевременной деградации, усиливая тем самым его «прямое» физиологическое воздействие. Такая гипотеза отпадает в связи с тем, что промоторная способность фенола находится в обратной зависимости от его антиокислительных свойств. По-видимому, следует искать другие причины для объяснения зтого важного и интересного явления

\section{Взаимосвязь токсичности и строения фенолов}

Накопленные к настоящему времени материалы оказались достаточными для качественного установления связей между токсичностью ряда фенолов (у животных и растений) и их структурой. Активность фенолов в этом аспекте также определяется количеством, характером и местом расположения заместителей в бензольном кольце. Обзор литературы по этому вопросу дан нами в предыдущем сообщении $\left[{ }^{30}\right]$, которое в основғом посвящено первой попытке количественного описания таких связей. Ниже приводятся в сжатом виде эти материалы, существенно дополненные в результате дальнейшей работы.

В табл. 3 приведены корреляционные уравнения типа модифицированных уравнений Хаммета-Тафта, выведенные для характеристики токсичности фенолов как функции их строения. Они основываются на данных литературы и результатах оригинальных токсикологических исследований. Характеристический показатель токсичности $\mathrm{DL}_{50}$ соответствует относительному количеству фенола, необходимому для гибели $50 \%$ подопытных объектов. В таблицу включены также данные из ра- 
Корреляционные уравнения для описания токсичности фенолов

\begin{tabular}{|c|c|c|c|c|c|}
\hline $\begin{array}{r}\text { Номер } \\
\text { серни }\end{array}$ & $\begin{array}{r}\text { Числа: } \\
\text { экспе-: } \\
\text { римен-: } \\
\text { тальных } \\
\text { точек }\end{array}$ & $\mathrm{У}_{\text {равнение }}$ & $r$ & $s$ & $\begin{array}{c}\text { Подопытные } \\
\text { объекты }\end{array}$ \\
\hline $1 \div$ & 4 & $\lg 1 / C=-0,7553 \Sigma \sigma_{i}+2,7445$ & 0,9677 & 0,018 & Мюти \\
\hline II & 5 & $\lg 1 / C=-1,0011 \Sigma \sigma_{i}+2,8978$ & 0.7994 & 0,081 & Крысы \\
\hline 111 & 4 & $\lg 1 / C=-0,8139 \Sigma \sigma_{i}+3,1447$ & 0,9185 & 0,039 & Кроликв \\
\hline IV & 4 & $\lg 1 / C=-4,0444 \Sigma \sigma_{i}+2,4034$ & 0,9600 & 0.064 & $\begin{array}{c}\text { Мыши (с прибавле } \\
\text { ннем тнрокснна) }\end{array}$ \\
\hline V & 25 & $\lg 1 / C=-4,9304 \Sigma \sigma_{i}+1,0309$ & 0,9396 & 0,385 & Растения \\
\hline VI & 7 & $\lg 1 / C=-2,6437 \Sigma \sigma_{i}+0,5539$ & 0,9164 & 0,308 & \\
\hline
\end{tabular}

боты $\left[{ }^{29}\right]$, в которой аналогичная корреляция произведена по $\sigma$-значениям Хаммета с внесением поправок на растворимость фенолов в жирах. Произведенная нами проверка корреляции по другим $\sigma$-шкалам приводит к заключению, что наилучшие результаты достигаются при использовании $\sigma_{R}{ }^{0}$-константы.

Наблюдаемая во всех случаях хорошая либо удовлетворительная корреляция $(r=0,92-0,97, s=0,02--0,04)$ подтверждается и при графической интерпретации рассматриваемой взаимосвязи на рисунке в координатах $\lg 1 / C-\Sigma \sigma_{i}$, где $1 / C=\mathrm{DL}_{50}$ (прямая 2). Судя по отрицательному значению константы $\varrho$, токсическое действие фенолов в организме, несмотря на всю сложность протекающих в нем процессов, осноєано на электрофильных реакциях: именно они лимитируют протекание Бсех прочих превращений, приводящих в конечном счете к гибели организма. Чувствительность такой реакции (см. табл. 3) колеблется от серии к серии, т. е. в зависимости от условий и подопытных объектов, в широких пределах. От общей установленной закономерности во всех сериях отклоняются орто-замещенные гомологи, но в противоположность предыдущему случаю - в сторону понижения биологической активности (токсичности).

\section{Заключение и выводы}

Взаимосвязь биологической активности фенолов (их канцерогеннопромоторной способности или токсичности) и особенностей электронной структуры их молекул, несмотря на всю сложность протекающих в живом организме процессов, поддается количественному описанию с помощью модифицированного уравнения Хаммета-Тафта, т. е. методами химической кинетнки. В большинстве случаев при этом удовлетворительно соблюдается принцип независимого и аддитивного влияния заместителей в бензольном кольце на реакционную способность оксигруппы (реакционного центра) в биологических процессах, особенно для метаи пара-замещенных гомологов.

Увеличению электронной плотности у реакционного центра соответствует усиление токсичности и ослабление промоторно-канцерогенных свойств фенолов. В первом случае лимитирующей стадией суммарной реакции фенолов в организме является электрофильная, во втором нуклеофильная. Поэтому, насколько можно судить по результатам ис- 
следования, фенолы, обладающие выраженной промоторно-канцерогенной способностью, малотоксичны, и наоборот. В соответствии с характером реакции специфическое отклонение орто-замещенных фенолов от общей закономерности связано с понижением их токсичности и усилением канцерогенности.

\section{ЛИТЕРАТ У Р А}

1. Пю ль м а н Б., Электронная биохимия, М., 1966.

2. Anders on Wm., Nature, 160, 892 (1947).

3. Pullmann A., Pullmann B., Cancérisation pas les Substances Chimiques et Structure Moléculaire. Masson, Paris, 1955.

4. Pullman n B., Pullm a n n A., Nature, 199, 464 (1963).

5. All is on A. C., Peover M. E., Gough T. A., Nature, 197, 764 (1963).

6. Szent-Györgyi A., Acad. Belge, Classe Sci. Mem., 33, 162 (1961)

7. Buu-Hoi N. P. et al., Experientia, 13, 375 (1953).

8. A 11 is on A. C., Nature, 197, 758 (1963).

9. All is on A. C., N a sh T., Nature, 199, 467 (1963).

10. Diner S., Electronic Aspects of Biochemistry, Academic Press Inc. N. Y. 1964.

11. Бед же р Г. М., Химические основы канцерогенной активности, М., 1966.

12. Gellhorn A., Cancer Res., 18, 510 (1958).

13. Ro e F. J. C., S a l a m a n M. H., Coh en J., Brit. J. Cancer, 13, 623 (1959).

14. T y e R., St e mmer K. L., J. Nat. Cancer Inst., 39, No. 2, 175 (1967).

15. Boutwell R. K., Rusch H. P., Bosch D. K., Proc. Am. Ass. Cancer Res., 2, No. 1,6 (1955).

16. Boutwel1 R. K., Rusch H. P., B ooth B., Proc. Am. Ass. Cancer Res. 2, No. 2, 96 (1956).

17. B outwell R. K., B os ch D. K., Cancer Res., 19, No. 4, 413 (1959).

18. Carruthers W., Johnst one R. A. W., Nature, 185, 762 (1960).

19. Wynder E. L., Hof f mann D., Deut. Med. Wochenschr., 88, No. 13, 623 (1963).

20. B outwel1 R. K., Phenolic Compounds Metab. Regul. (Chapt. 5), Ed. Finkle a. Runcles, California, Montreal, 1967.

21. Эй зе н О., А р о И., Изв. АН ЭССР, Сер. физ.-матем. и техн. наук, 7, № 3, 227 (1958).

22. Губергриц М. Я., Боговский П. А. и др., Матерналы ІІ конф. онкологов Прибалтики, Таллин, 1967, с. 138.

23. Лилле Ю., Кундель Х., Сланц. и хим. пром-сть, Таллин, № 6,17 (1965).

24. Бурл акова Б., Га инцев а В. Д., Эм ануэль Н. М., Изв, АН СССР, Сер. бнол., 31, № 4, 511 (1966).

25. T a f t R. W., Ehrenson S. a. o., J. Am. Chem. Soc., 81, 5352 (1959).

26. T aft R. W., Price E. a. o., J. Am. Chem. Soc., 85, 3146 (1963).

27. Коппель И. А., Маремяэ В. А., Туулметс А. В., Тартуск. гос. ун-т, Сб. Реакционная способность органических соединений, 2, № 3, 39 (1965).

28. К и рсо У. Э., Гу бе ргриц М. Я., К у й в К. А., Тартуск, гос. ун-т, Сб. Реакционная способность органических соединений, 3 , № 3,33 (1966).

29. Fujita Toshio, J. Med. Chem., 9, No. 6, 797 (1966).

30. К и р со У. Э., М а а зик К. Х., Сб. Вопросы гигиены труда и профессиональной патологии Эстонской ССР, Таллин, 1969 (в печати).

\section{Институт химии \\ Академии наук Эстонской ССР}

Поступила в редакцию 16/IX 1968 
M. GUBERGRITS, U. KIRSO

\section{FENOOLIDE STRUKTUUR, REAKTSIOONIVOIMELISUS JA BIOLOOGILINE AKTIIVSUS}

Käsitletakse fenoolide bioloogilist (toksilist ja kantserogeenset) aktiivsust sōltuvalt elektrontihedusest reaktsioonitsentris (OH-grupis). Leiti, et elavas organismis toimuvate protsesside keerukusele vaatamata on vöimalik keemilise kineetika meetodite abil, kasutades Hammett-Tafti võrrandit, kvantitatiivselt seostada ühendi bioloogilist aktiivsust tema struktuuriga. Vōrrand rahuldas enamikul vaadeldud juhtumitel: korrelatsioonikoefitsient $r=0,95 \ldots 0,99$, standardne hälve $s=0,002 \ldots 0,040$. Paralleelselt elektrontiheduse suurenemisega reaktsioonitsentris suureneb ka fenooli toksilisus, samal ajal aga väheneb tema kantserogeensus. Esimesel juhul on limiteerivaks staadiumiks elektrofiilne, teisel juhul nukleofiilne reaktsioon. Järelikult on mürgisemad fenoolid nörgema kantserogeense toimega. Oldisest seaduspärasusest kalduvad kōrvale ortoasendatud fenoolid, millede toksilisus on madalam, kantserogeensus aga kõrgem.

M. GUBERGRITS, U. KIRSO

\section{STRUCTURE, REACTIVITY AND *BIOLOGICAL ACTIVITY OF PHENOLS}

\section{Summary}

A method of quantitative correlation biological activity (toxicity and carcinogenity) and chemical structure of phenols, using substituent constants $\sigma_{R}{ }^{\circ}$, has been developed and proved. A satisfactory fit of Hammett-Taft's equation (correlation coefficient $r=0.95-0.99$ and a value of standard deviation $s=0.002-0.040$ ) seems to confirm the fair applicability of the additivity rule. The toxicity of phenols inverse to carcinogenity seems to decrease proportionally with the growth of electronic density of the hydroxylic group as a reaction center. The limit step of the toxic action in vivo of phenols seems to be an electrophilic reaction, whereas that of the carcinogenic activity is a reaction of nucleophilic type. As a rule, the most toxic phenols are stated to be not carcinogenic. In most cases, the ortho substituted phenols might be more carcinogenic and less toxic. 